\title{
Parallel Evolution of Cortical Areas Involved in Skilled Hand Use
}

\author{
Jeffrey Padberg, ${ }^{1}$ João G. Franca, ${ }^{3}$ Dylan F. Cooke, ${ }^{1}$ Juliana G. M. Soares, ${ }^{3}$ Marcello G. P. Rosa, ${ }^{4}$ Mario Fiorani Jr, ${ }^{3}$ \\ Ricardo Gattass, ${ }^{3}$ and Leah Krubitzer ${ }^{1,2}$ \\ ${ }^{1}$ Center for Neuroscience, ${ }^{2}$ Department of Psychology, University of California, Davis, California 95618, ${ }^{3}$ Instituto de Biofisica Carlos Chagas Filho, \\ Universidade Federal do Rio de Janeiro, CEP 21941-902, Rio de Janeiro, Brazil, and ${ }^{4}$ Department of Physiology, Monash University, Melbourne, Victoria \\ 3800, Australia
}

Dexterous hands, used to manipulate food, tools, and other objects, are one of the hallmarks of primate evolution. However, the neural substrate of fine manual control necessary for these behaviors remains unclear. Here, we describe the functional organization of parietal cortical areas 2 and 5 in the cebus monkey. Whereas other New World monkeys can be quite dexterous, and possess a poorly developed area 5 , cebus monkeys are the only New World primate known to use a precision grip, and thus have an extended repertoire of manual behaviors. Unlike other New World Monkeys, but much like the macaque monkey, cebus monkeys possess a proprioceptive cortical area 2 and a well developed area 5 , which is associated with motor planning and the generation of internal body coordinates necessary for visually guided reaching, grasping, and manipulation. The similarity of these fields in cebus monkeys and distantly related macaque monkeys with similar manual abilities indicates that the range of cortical organizations that can emerge in primates is constrained, and those that emerge are the result of highly conserved developmental mechanisms that shape the boundaries and topographic organizations of cortical areas.

Key words: area 2; area 5; posterior parietal cortex; primate evolution; reaching; grasping

\section{Introduction}

All species possess morphology and behaviors associated with their ecological niche. For instance, the aerial precision of bats and the agility of mountain goats are attributable to specialized forelimb morphology such as wings and hooves. Likewise, the human hand is a derivation of the forelimb that allows us to perform remarkable feats of manual precision (Mountcastle, 2005a). Interestingly, wings, hooves, and hands evolved independently from each other, but all originated from this highly conserved feature of the vertebrate body plan. Despite this diversity, the persistence of basic forelimb structure indicates that the ways in which body morphologies evolve is highly constrained (Patel, 2003; Showell et al., 2004).

Of equal importance to forelimb function is the neural circuitry generating behaviors associated with the forelimb, which includes cortical and subcortical structures that process inputs from mechanosensory and proprioceptive receptors of the forelimb, and motor areas that plan and execute movements of the

\footnotetext{
Received June 9, 2007; revised July 23, 2007; accepted July 30, 2007.

This work was supported by a grant from the McDonnell Foundation, National Institute of Neurological Disorders and Stroke Grant R01-NS035103-11 (L.K.), and a grant from the Australian Research Council (M.G.P.R.). Support from Programa de Núcleos de Excelência, Fundação de Amparo à Pesquisa do Rio de Janeiro, Financiadora de Estudos e Projetos, and Conselho Nacional de Pesquisa was awarded to J.G.F., J.G.M.S., M.F., and R.G. at the Universidade Federal do Rio de Janeiro. We thank Sarah Long, Deborah Hunt, DeLaine Larsen, and Rowan Tweedale for helpfu comments on this manuscript, and to Sally Mendoza, Carmel Stanko, and John Capitanio for assistance with titi monkey photography.

Correspondence should be addressed to Leah Krubitzer, Center for Neuroscience, University of California, Davis, 1544 Newton Court, Davis, CA 95618. E-mail: lakrubitzer@ucdavis.edu.

DOI:10.1523/JNEUROSCI.2632-07.2007

Copyright $\odot 2007$ Society for Neuroscience 0270-6474/07/2710106-10\$15.00/0
}

limb (Castiello, 2005; Mountcastle, 2005c). Because comparative studies indicate that cortical field evolution is constrained in location, organization, and connectivity, we hypothesized that cortical regions associated with hand use coevolve in predictable ways in primates with similar hand morphology and use. Here, we examined the organization of somatosensory cortex in the New World cebus monkey whose hand morphology and use parallel that of the well studied Old World macaque.

Whereas other New World species such as squirrel monkeys exclusively use a power grip, cebus monkeys frequently use a precision grip in which the thumb and forefinger are brought into contact with one another to manipulate small objects, or engage in goal-directed tool use (Fragaszy, 1983; Christel and Fragaszy, 2000; Spinozzi et al., 2004). The changes to hand morphology that made a precision grip possible are different in cebus and macaques, suggesting that the precision grip evolved independently after the divergence of New and Old World monkeys (Napier and Napier, 1967; Fleagle and Simons, 1995; Rose, 1996). Comparisons of nervous system organization reveal that macaques and cebus have robust corticospinal terminations in the ventral horn laminas of the spinal cord innervating individual digits of the hand, whereas squirrel monkeys have a restricted projection zone (Bernhard et al., 1953; Tigges et al., 1979; Kuypers, 1981; Heffner and Masterton, 1983; Bortoff and Strick, 1993; Maier et al., 1997; Nakajima et al., 2000). Furthermore, cortical regions that process inputs from the hand are well developed in the parietal cortex of Old World monkeys (Fig. 1). In contrast, in most New World monkeys, fewer cortical fields are present in the corresponding location. Specifically, two of these fields, areas 2 and 5, are well developed in macaques, but 
a

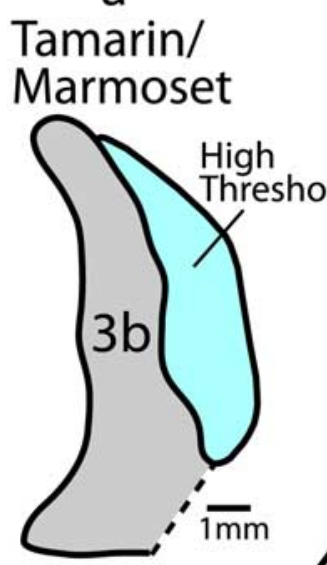

Carlson et al., 1986

Huffman et al., 2001

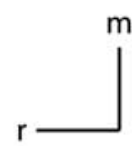

m

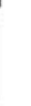

b

\section{Owl Monkey}

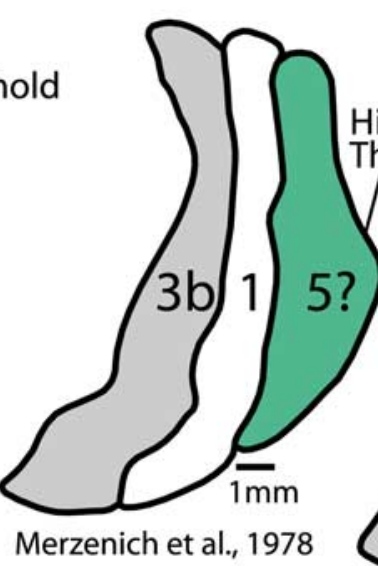

Merzenich et al., 1978
C

Macaque Monkey

\section{Macaque Monkey}

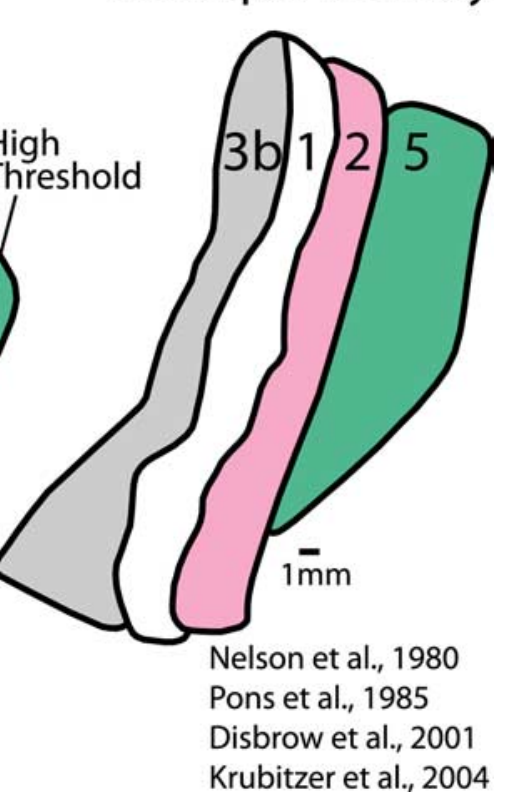

Figure 1. $\boldsymbol{a}-\boldsymbol{c}$, Schematic diagrams of marmoset $(\boldsymbol{a})$, owl monkey $(\boldsymbol{b})$, and macaque monkey $(\boldsymbol{c})$ parietal areas involved in object exploration and reaching and grasping. Note that in less-dexterous New World species, these areas are less well developed or absent $(\boldsymbol{a}, \boldsymbol{b})$, whereas in the dexterous Old World macaque $(\boldsymbol{c})$, these areas are well developed and include four parietal fields, areas $3 b, 1,2$, and 5 .

are absent or poorly developed in New World monkeys (Padberg et al., 2005).

Our goal was to examine the organization of cortex in the expected location of areas 2 and 5 in cebus, and compare this with macaques. We demonstrate a very similar organization in cebus, suggesting limitations in the types of cortical organization that evolve, likely because of the synergistic action of intrinsic and extrinsic factors common to both groups.

\section{Materials and Methods}

The organization of areas 2 and 5 was examined in three adult cebus monkeys (Cebus apella) weighing 1.8-2.1 kg using standard multiunit electrophysiological recording techniques combined with architectonic analysis. Experimental protocols conformed to National Institutes of Health guidelines.

Electrophysiological recording. Animals were initially anesthetized with intramuscular injections of ketamine hydrochloride $(10 \mathrm{mg} / \mathrm{kg})$ and $x y-$ lazine $(1 \mathrm{mg} / \mathrm{kg})$, and then administered atropine $(0.04 \mathrm{mg} / \mathrm{kg})$. Once anesthetized, the animals were cannulated. Surgical levels of anesthesia were maintained with supplemental doses of ketamine and xylazine delivered intramuscularly or intravenously. A continuous infusion of lactated Ringer's solution $(6 \mathrm{ml} / \mathrm{kg} / \mathrm{h})$ was given intravenously via a calibrated syringe pump. Throughout the experiment the animal's heart rate, respiration rate, and temperature were monitored and maintained. Once the animal was anesthetized and stabilized, the skin was cut, the temporalis muscle was retracted and a craniotomy was made over the anterior and posterior parietal cortex.

Electrophysiological recordings were obtained with tungsten-invarnish microelectrodes (1-5 M $\Omega$ at $100 \mathrm{~Hz}$; A-M Systems, Sequim, WA). The electrode was placed perpendicular to the cortical surface, and a calibrated micromanipulator (Kopf Instruments, Tujunga, CA) was used to lower the electrode in increments of $500 \mu \mathrm{m}$ into the cortex. The electrode was moved in the $x-y$ plane in increments of 500-750 $\mu \mathrm{m}$. Once the electrode was in place, the body surface was stimulated, and the receptive fields of neurons at that cortical site were drawn on diagrams of the

monkey's body. The neural response was amplified, filtered, and monitored through a loudspeaker. Cutaneous stimulation consisted of light displacements of skin with a fine probe, and light brushing of hairs and skin. Light to moderate taps, digit and limb manipulation, and light pressure were used to stimulate deep receptors of the muscles, joints, and skin. In all animals, the contralateral and ipsilateral body surface, joints and musculature were stimulated. Selected recording sites in these experiments were marked by coating the recording electrode with a $10 \%$ solution of diamidino yellow (DY; Sigma, St. Louis, MO), and then reinserting the electrode into the cortex at sites either on the surface of cortex or into the depths of the intraparietal sulcus (IPS). This method allowed us to readily identify selected electrode penetrations, determine electrode angle for the penetrations into the banks of sulci, and relate recording sites to histologically processed tissue.

Histological processing. After completion of the electrophysiological mapping session, each animal was administered a lethal dose of sodium pentobarbitone and transcardially perfused with $0.9 \%$ saline, followed by $4 \%$ paraformaldehyde in phosphate buffer, and then $4 \%$ paraformaldehyde in $10 \%$ sucrose phosphate buffer, $\mathrm{pH}$ 7.2-7.4. The brain was removed from the skull and, in two cases, each cortical hemisphere was carefully removed from the underlying thalamus and brainstem. One hemisphere for each of these two cases was manually flattened and then placed beneath a lightly weighted microscope slide overnight in phosphate buffer with $30 \%$ sucrose. This hemisphere was later sectioned tangentially at $55 \mu \mathrm{m}$. The remaining hemispheres from these two cases were left intact in phosphate buffer with $30 \%$ sucrose before sectioning horizontally at $80 \mu \mathrm{m}$. The thalami in all cases were placed in phosphate buffer with $30 \%$ sucrose overnight and were sectioned for later analysis in a related study. In the third case, the brain was left intact and placed into phosphate buffer with $30 \%$ sucrose. In this case, the entire brain was sectioned horizontally at $60 \mu \mathrm{m}$. Alternate series of cortical sections were processed for Nissl or myelin (Gallyas, 1979).

Data analysis. In the first stage of our analysis, electrophysiological maps of the brain were made by analyzing receptive field positions and stimulus preferences at all sites, and drawing interpolated borders between different body part representations. The angle of our electrode penetrations in the rostral bank of the IPS was determined from electrode tracks and the DY probes on Nissl-stained and/or myelin-stained sections. Next, we used a camera lucida to draw architectonic boundaries from the entire series of tangentially sectioned tissue stained for myelin. These drawings also included the outline of the section, blood vessels, tissue artifacts, DY probes, and electrode angles. By aligning all of these landmarks, architectonic boundaries throughout the entire series of sections were obtained. This architectonic reconstruction was directly related to the electrophysiological recordings by matching the probes drawn on our picture of the brain with those found in the histologically processed tissue. In this way, a single comprehensive reconstruction of the architectonic boundaries relative to the electrophysiological recording sites was made. For horizontally sectioned tissue, we used a camera lucida to draw architectonic boundaries from series of tissue stained for myelin and Nissl, at a scale that matched an enlarged diagram of our electrode penetrations obtained during the mapping session. These drawings included the outline of the section, blood vessels, tissue artifacts, DY probes, and electrode tracks. We then artificially "unfolded" the series of sections similar to methods described previously by Van Essen and Maunsell (1980) and Krubitzer et al. (1995). By flattening and aligning the series of sections using DY probes, a cortical surface reconstruc- 
tion could be made and aligned with the photograph of electrode penetrations. This allowed us to produce a comprehensive reconstruction that included architectonic boundaries, sulcal landmarks, surface electrode penetrations, and the entire extent and angle of electrode penetrations made into the central and intraparietal sulcus. Final drawings and photomicrographs were generated and assembled using Adobe (San Jose, CA) Photoshop and Illustrator software packages.

\section{Results}

The cortex on the postcentral gyrus and within the intraparietal sulcus of the cebus was mapped in detail using electrophysiological methods. Our primary goal was to examine the organization of the cortex in the expected location of cortical fields 2 and 5. The organization of areas $3 \mathrm{~b}$ and 1 have been documented previously in cebus monkeys (Felleman et al., 1983) and, although recording sites in area 1 are illustrated, the organization of these fields will not be described here.

\section{Organization of area 2}

Dense electrophysiological recordings indicate that cebus monkeys have a clearly defined area 2 . This is surprising because this field does not appear to be present in any other New World monkey in which this region has been electrophysiologically explored [owl monkey (Merzenich et al., 1978), squirrel monkey (Sur et al., 1982), and titi monkey (Coq et al., 2004; Padberg et al., 2005)]. Despite the apparent independent emergence of area 2 in cebus monkey, aspects of its organization are remarkably similar to those of area 2 in Old World macaque monkeys. For instance, neurons in area 2 responded to stimulation of deep and cutaneous receptors, although in cebus monkeys, there is a greater proportion of recording sites in which neurons respond to cutaneous stimulation. When all recording sites in area 2 were considered together, a complete representation of the contralateral body was observed (Figs. 2, 3). Furthermore, like area 2 in macaque monkeys, area 2 in cebus monkeys is dominated by the representation of the hand and face. The body representation was readily distinguished from adjacent fields in that separate mediolateral progressions of recording sites yielded separate, parallel representations of the body in areas 1 and 2, and a parallel representation of the forelimb in the caudally located area 5 (Fig. 4). We did not attempt to map the cortex lateral to the hand representation, in the expected location of the face representation. However, a few recording sites at the lateral extreme of the recording grid did result in receptive fields located in the snout and chin (Figs. 2, 3), suggesting that area 2 extends further laterally.

Within area 2, the representations of the foot and toes/hindlimb were located most medially. In one case in which the electrode angle was optimal for recording neurons in layer IV, numerous recordings were made on the medial wall, and a large representation of the prehensile tail was observed (Fig. 2). In another case, representations of the anogenital skin were observed lateral to the toe representations (Fig. 3). The trunk was represented lateral to the hindlimb and toes and occupied relatively less cortical territory than the trunk representation in area 1. Lateral to the trunk representation was that of the forelimb, and lateral to this were the representations of the wrist and elbow, followed by portions of the hand representation. A relatively large portion of area 2 lateral to the hand and wrist representations was occupied by the representations of individual digits (Figs. 2, 3). The ulnar digit representation was located medially, and the radial digits more laterally. Both individual and multiple digit representations were observed at recording sites in area 2. Receptive field sizes observed for neurons in area 2 were typically larger than those in area 1 , although this was not quantitatively assessed. At two sites neurons in area 2 had bilateral receptive fields (Fig. $5 C)$. In regions of high recording site density, and particularly in the forelimb representations, the electrophysiological borders of area 2 were identified by a reversal in a rostrocaudal progression of receptive fields across cortical field boundaries (Fig. 5B).

In cortex that has been flattened and cut tangentially, area 2 is moderately myelinated, and can be distinguished from the rostrally located area 1 , which is lightly myelinated. In brains that were sectioned horizontally and stained for Nissl, area 2 appears more homogeneous than areas $3 \mathrm{~b}$ and 1 , but possess a moderately packed and wide layer IV (Fig. 6).

\section{Organization of area 5}

Although single-unit recording experiments and limited multiunit recordings have been performed in area 5 of macaque monkeys (Mountcastle et al., 1975; Pons et al., 1985; Ferraina and Bianchi, 1994; Lacquaniti et al., 1995; Snyder et al., 1997; Taoka et al., 2000; Debowy et al., 2001) (for review see Kalaska, 1996; Wise et al., 1997; Iwamura, 2000), the present data allow the most comprehensive description of the topographic organization of this area in any primate to date.

Neurons in area 5 responded to stimulation of deep or cutaneous receptors on the contralateral hand, forelimb, and shoulder, and in a few instances, responded to both cutaneous and deep stimulation (Figs. 2,3). The most striking feature of area 5 is that it is dominated by the representation of the forelimb and hand, with very little space devoted to other body parts. Indeed, in the case in which the mediolateral extent of the IPS was examined most extensively (Fig. 3, R0503), neurons at all but five recording sites in area 5 responded exclusively to stimulation of the digits, hand, or portions of the forelimb (the five remaining sites had receptive fields on the upper trunk and/or forelimb). In the other case illustrated (Fig. 2, R0502) a small representation of the hindlimb was also found, and was near the medial limit of the field.

The topography of area 5 was less precise than that of area 2, but generally the proximal forelimb and adjacent trunk were represented medial to the distal forelimb and hand (Figs. 2, 3). In one case (R0502), the representations of the hand and forelimb were present across a large mediolateral extent of area 5, and hand representations were sometimes located between forelimb representations. At one recording site, neurons were responsive to stimulation of the contralateral wrist and ipsilateral elbow (Figs. $2,5 C)$, an observation that suggests either a close apposition of neuronal populations representing different body parts or nontopographic convergence of inputs. In this same case, a large representation of the hand was observed laterally in the field, and lateral to this was the representation of the chin (Fig. 2). In a second case (R0503), the representations of the wrist, elbow, and distal and proximal forelimb were found in multiple locations at the medial portions of area 5, and the representation of the digits and hand were represented lateral to this (Fig. 3). Finally, in a third animal (R0501) (data not shown), a representation of the distal forelimb was located among representations of proximal forelimb, hand, wrist, and elbow. In this case, several sites lateral to the elbow and ventral forelimb representation contained neurons that were unresponsive to any of the stimuli we used. However, moving more laterally, near the tip of the IPS, representations of the forelimb, hand, and trunk were again observed, followed by the representations of the digits and glabrous hand. There were a few sites in which neurons responded to the lips, face, neck, and proximal forelimb. In summary, although a mediolateral 

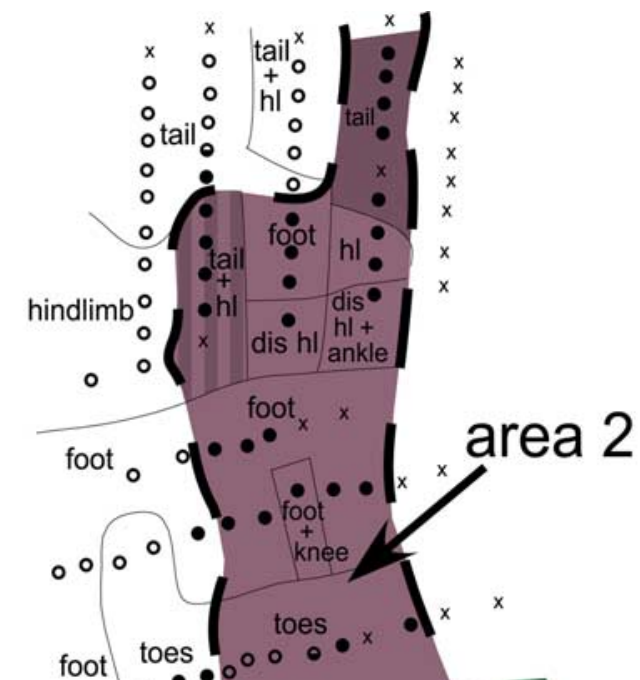

-
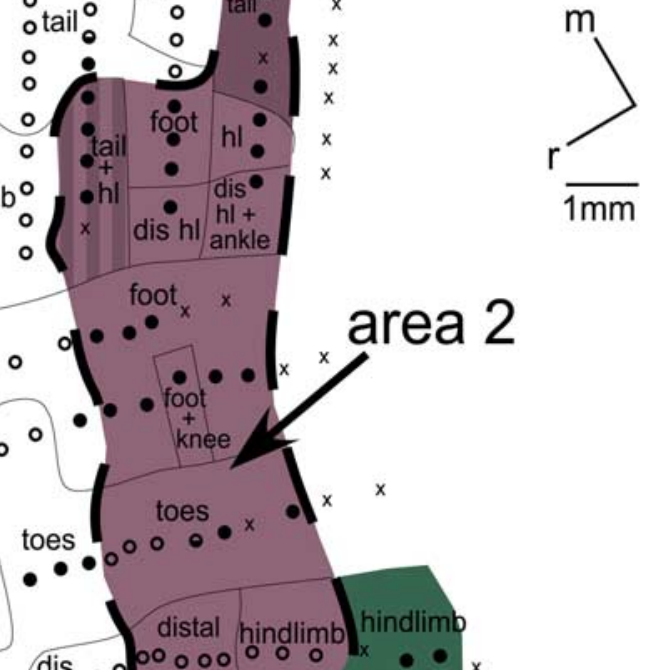

$\overline{1 \mathrm{~mm}}$

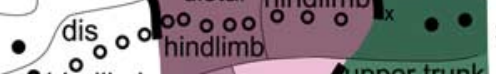

- hindlimb pupper trunk

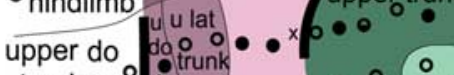

trunko o tr trun

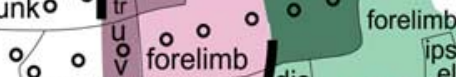

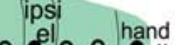

dis dis oo 00 elo o hand

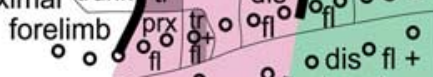
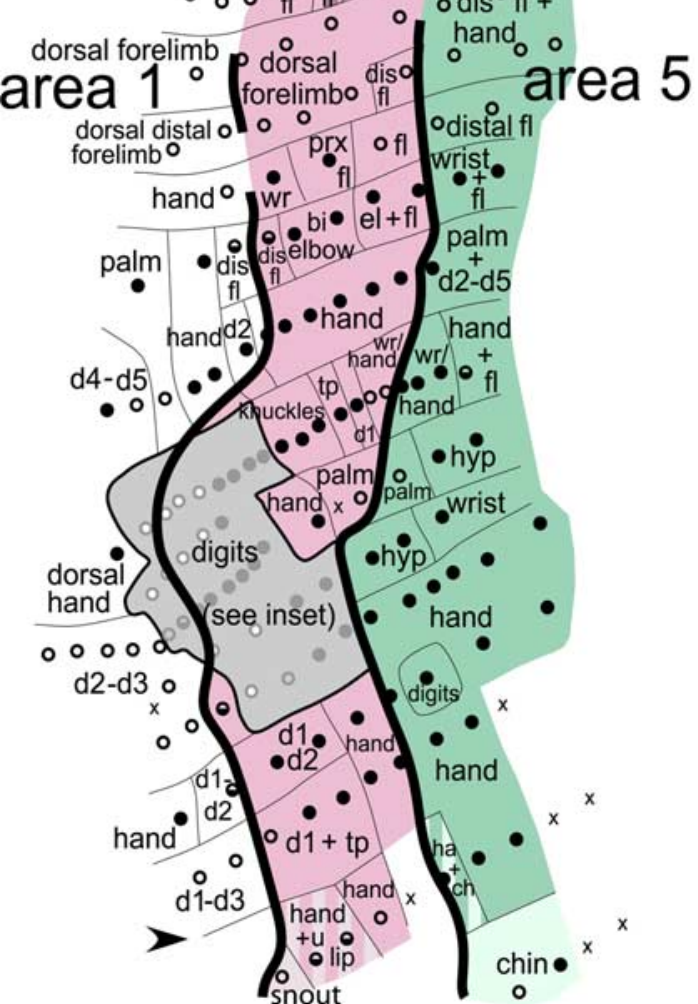

Case 0502
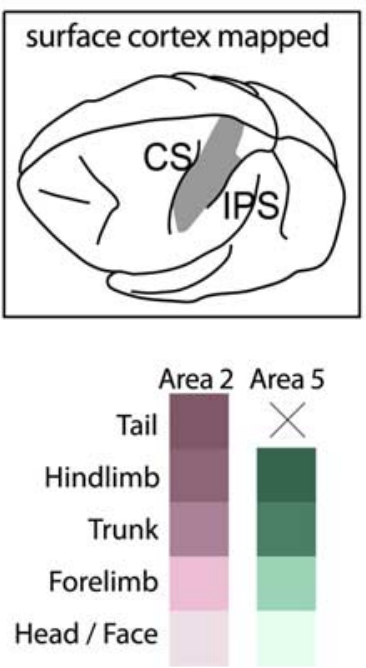

Abbreviations

$\begin{array}{ll}\text { bi } & \text { bilateral } \\ \text { ch } & \text { chin } \\ \text { do } & \text { dorsal } \\ \text { d1-d5 } & \text { digits 1-5 } \\ \text { dis } & \text { distal } \\ \text { el } & \text { elbow } \\ \text { fl } & \text { forelimb } \\ \text { glab } & \text { glabrous }\end{array}$

hl hindlimb

hyp hypothenar pad

lat lateral

mid middle

p1-p5 pads 1-5

prx proximal

sh shoulder

tp thenar pad

tr trunk

upper

ventral

wrist

response $\left.\right|_{0} ^{x}$

no response

cutaneous

cut. + deep

deep

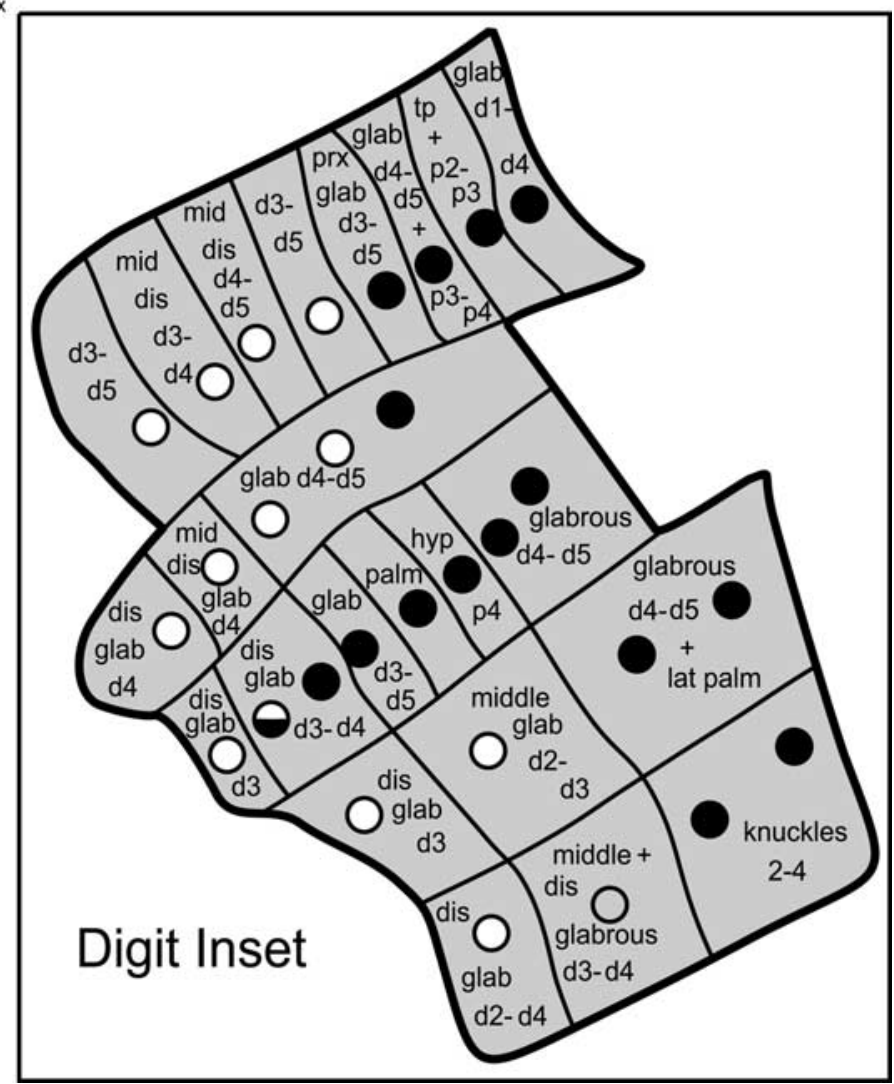

Figure 2. Electrophysiological map of case R0502. Most recording sites were located on the postcentral gyrus, one penetration was made into the IPS, and several penetrations were made along the cortical medial wall of the hemisphere. The inset at the top right illustrates the region of the cortex that was explored. In this case, neurons within area 1 responded predominantly to stimulation of cutaneous receptors (open circles) on the contralateral body, although several sites contained neurons that responded to stimulation of deep receptors (filled circles), on the contralateral body. Neurons in area 2 responded to stimulation of cutaneous or deep receptors of the contralateral body and a few sites had neurons with bilateral receptive fields. Neurons in area 5 responded mostly to stimulation of deep receptors on the contralateral body, although at a few sites neurons responded to stimulation of cutaneous receptors. In this case, area 2 contained a nearly complete representation of the contralateral body with a mediolateral progression from tail to hand (maroon and pink shading). In contrast, area 5 was dominated by the representations of portions of the forelimb and hand (light green) with neurons at only a few sites having receptive fields on other body parts such as the hindlimb and upper trunk medially (dark green), and the cheek and chin laterally (very light green). Hatched regions depict sites in which neurons responded to stimulation of more than one body part. Solid lines mark architectonic boundaries, dashed lines mark approximate boundaries. Arrowhead depicts location of hand/face border. m, Medial; r, rostral; CS, central sulcus. 
topography could be distinguished to some extent, it was less precise compared with the topography observed in areas $3 \mathrm{~b}, 1$, and 2, and was a mosaic-like representation that was variable between individuals. Receptive fields for neurons in area 5 were, on average, much larger than for neurons in areas 1 and 2 (Fig. 5A), and often occupied large portions of the palm, or a few adjacent digits (Fig. 4C). In few instances, receptive fields were limited to a single digit. Only one recording site in area 5 in one animal had neurons with a bilateral receptive field.

Area 5 was observed to stain moderately for myelin in cortex that was cut tangentially, and occupied most of the rostrolateral portion of the upper bank of the IPS. In horizontally sectioned cortex that was stained for Nissl substance, layers IV and VI in area 5 had more densely packed neurons compared with those in the same layers in area 2 (Fig. 6). The caudal boundary of area 5 with adjacent intraparietal sulcus areas was sometimes difficult to identify, but where possible, was determined by a decrease in the density of cells in layer IV and lighter myelination (Rosa et al., 1993).

Results from the present investigation indicate that, like macaque monkeys, parietal cortex in cebus monkeys contains a cortical area 2 that is similar in location and topographic organization to that of area 2 described in Old World macaque monkeys, but not to similar regions of cortex in other New World monkeys. Our complete description of area 5 in cebus monkeys indicates that it too is like that of similarly located regions in macaque monkeys. However, the present data extends previous studies in macaques by demonstrating an enormous representation of the forelimb and hand, and a variable, mosaic organization of area 5 that resembles that of motor cortex in primates, rather than somatosensory cortex.

\section{Discussion}

In this investigation we observed well differentiated areas 2 and 5 in the cebus monkey that are remarkably similar in organization to these fields in macaques, but are absent or poorly differentiated in other New World monkeys. Examination of cranial morphology of early primates (Fleagle, 1986; Fleagle and Simons, 1995) and comparative analysis indicate that these areas were not present in the common simian ancestor. Rather, areas 2 and 5 emerged independently in Old World macaques and New World cebus monkeys, and do not represent true homology, but latent homology (Hall, 2003; Rutishauser and Moline, 2005).
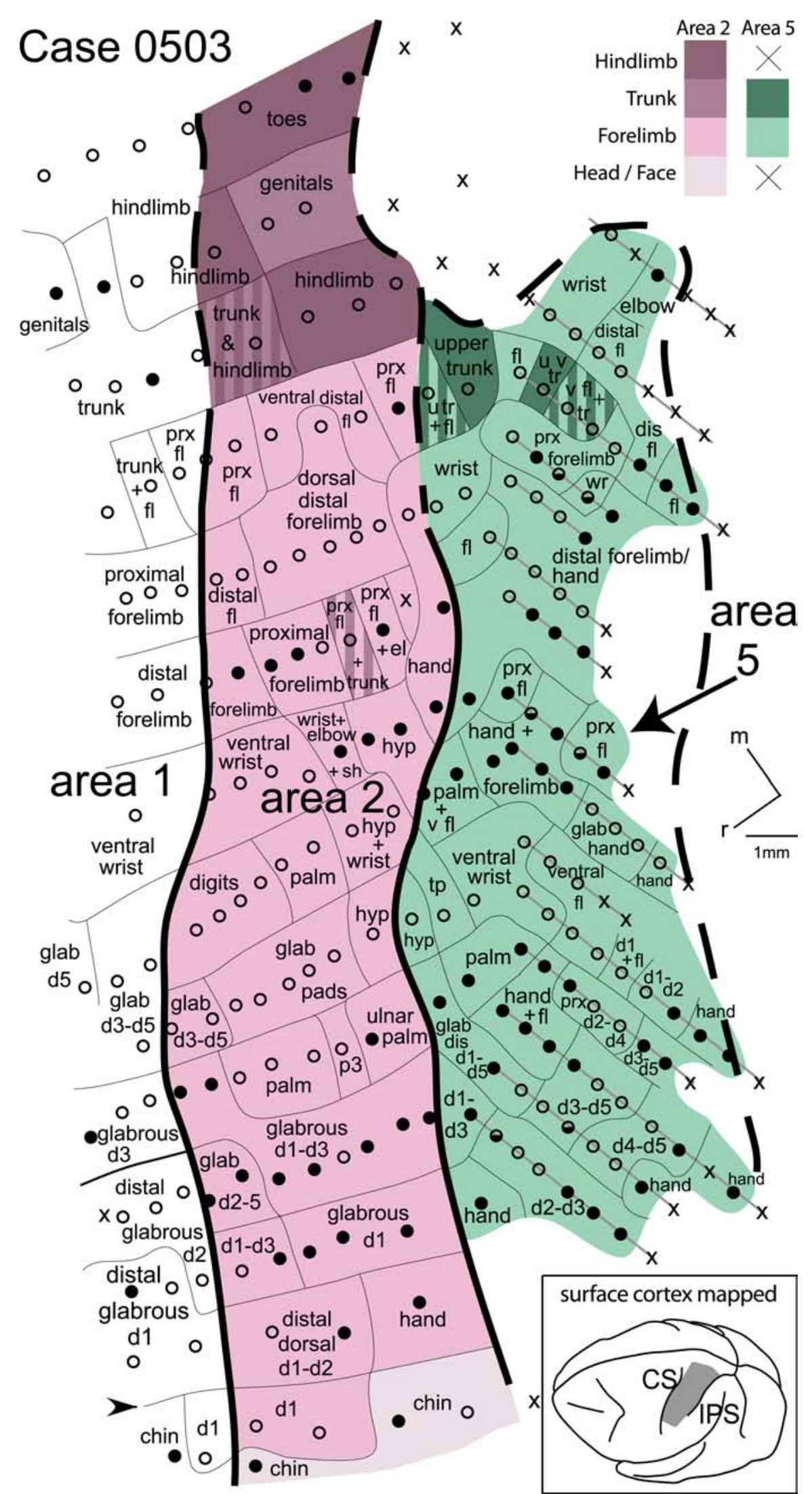

Figure 3. Electrophysiological map of case R0503. In this case, a number of electrode penetrations were made into the rostral bank of the IPS as well as on the post central gyrus. The organization of area 2 was similar to that of area 2 in other cases (Fig. 2). As in the other cases, area 5 was dominated by the representations of the forelimb, hand and digits. Conventions are as in previous figures. 

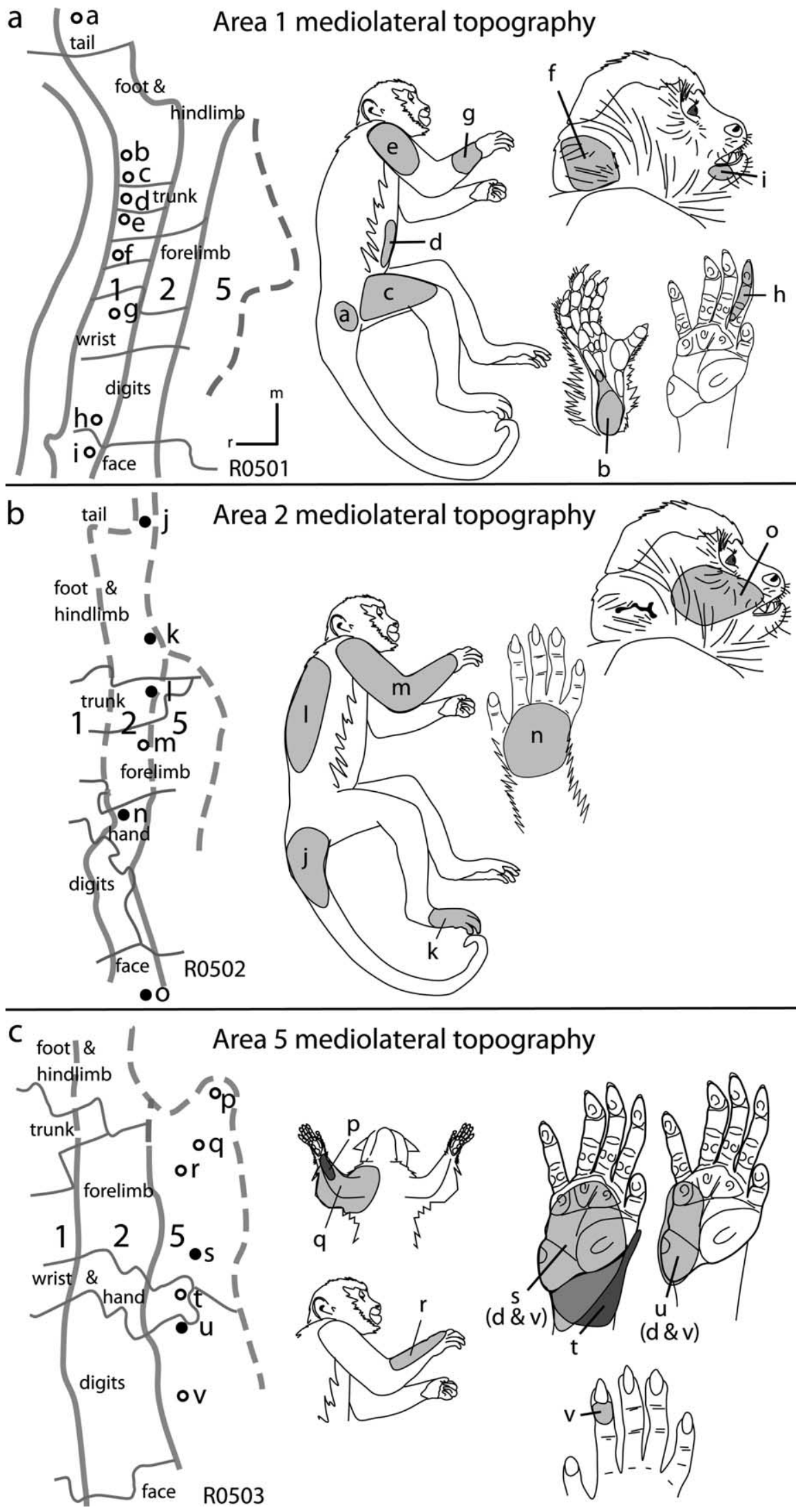

Figure 4. $\boldsymbol{a}-\boldsymbol{c}$, Mediolateral progressions of cortical representations in area $1(\boldsymbol{a})$, area $2(\boldsymbol{b})$, and area 5 (c). Lowercase letters in $\boldsymbol{a}$-cmark electrode penetrations. Corresponding receptive fields (gray) for neurons at those sites are marked on drawings of the body to the right. Relatively precise topographic arrangement of body representations was observed mediolaterally in areas 1 (a) and 2 (b) in cases R0501 and R0502, respectively. Mediolateral arrangement of representations in area 5 (c) demonstrates that this field is dominated by the representations of the hand and forelimb. Conventions are as in previous figures.
Areas 2 and 5

Although this is the first functional description of area 2 in any New World monkey, the organization of area 2 has been described previously in macaques (Pons et al., 1985) and is similar to area 2 in cebus. For example, area 2 in both species is dominated by the representation of the hand and face, and neurons respond to stimulation of deep (Hyvärinen and Poranen, 1978; Taoka et al., 1998, 2000; Iwamura et al., 2002) and cutaneous receptors (Ageronioti-Bélanger and Chapman, 1992). In macaques, neurons in area 2 respond to passive and active flexion of joints (Wolpaw, 1980; Gardner, 1988), are modulated during grasping (Debowy et al., 2001), and participate in the online correction of movement (Burbaud et al., 1991). Lesions that include area 2 affect the discrimination of object size, shape, and curvatures (Randolph and Semmes, 1974; Carlson, 1981; Murray and Mishkin, 1984). Noninvasive imaging studies demonstrate that area 2 is also present in humans (Fig. 7) (Moore et al., 2000). Although cortex caudal to area 1 has been explored in other New World monkeys, area 2 has not been found (for review, see Padberg et al., 2005) (Fig. 7).

We also observed a well developed area 5 in cebus monkeys. As in macaques, area 5 is dominated by the representation of the hand and forelimb (Pons et al., 1985; Taoka et al., 1998; Krubitzer and Disbrow, 2007). In cebus, area 5 contains a fractured map in which the forelimb and portions of the hand are represented multiple times, much like the organization of motor cortex, and this organization varies between individuals. Thus, portions of posterior parietal cortex that may include area 5 could be considered an elaboration of motor cortex in primates (Graziano et al., 2000; Stepniewska et al., 2005), and the variable organization of area 5 suggests that the ultimate organization may be use dependent.

This view is supported by single-unit studies in macaques that demonstrate that area 5 is involved in motor preparation (Burbaud et al., 1991; Snyder et al., 1997), in preshaping the hand before grasping an object (Debowy et al., 2001), and in generating body- or shoulder-centered coordinates for reaching (Ferraina and Bianchi, 1994; Lacquaniti et al., 1995; Iriki et al., 1996, Andersen et al., 1997; Graziano et al., 2000; Kalaska, 1996), which can be modified by experience (Iriki et al., 1996; Graziano et al., 2000). Lesions that include area 5 cause deficits in the coordination of arm and hand velocity, the postural relationship between the hand and wrist, and the coordination of the hand in shouldercentered space (Rushworth et al., 1997). In 


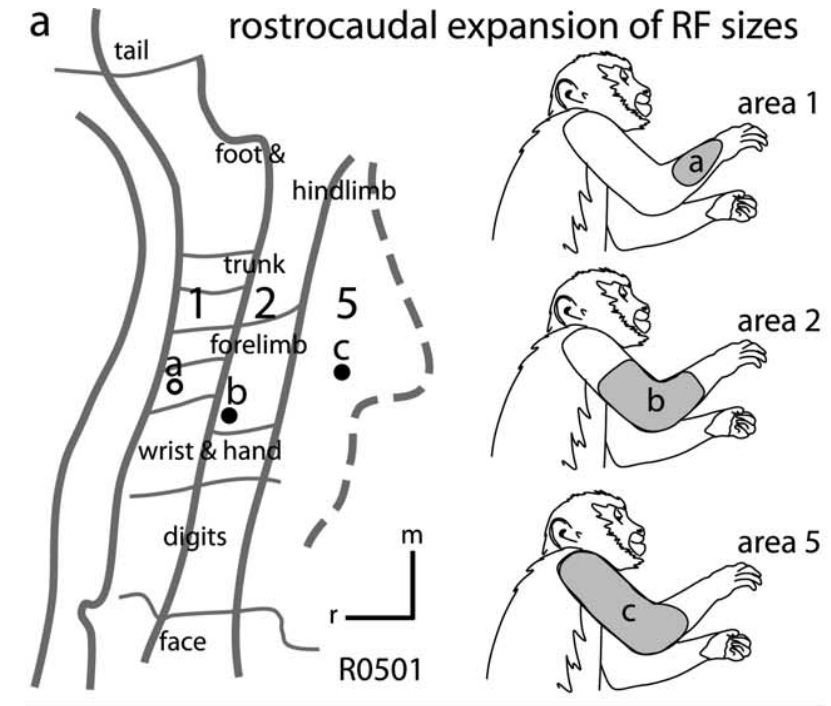

b foot \& RF reversal at area $2 / 5$ border
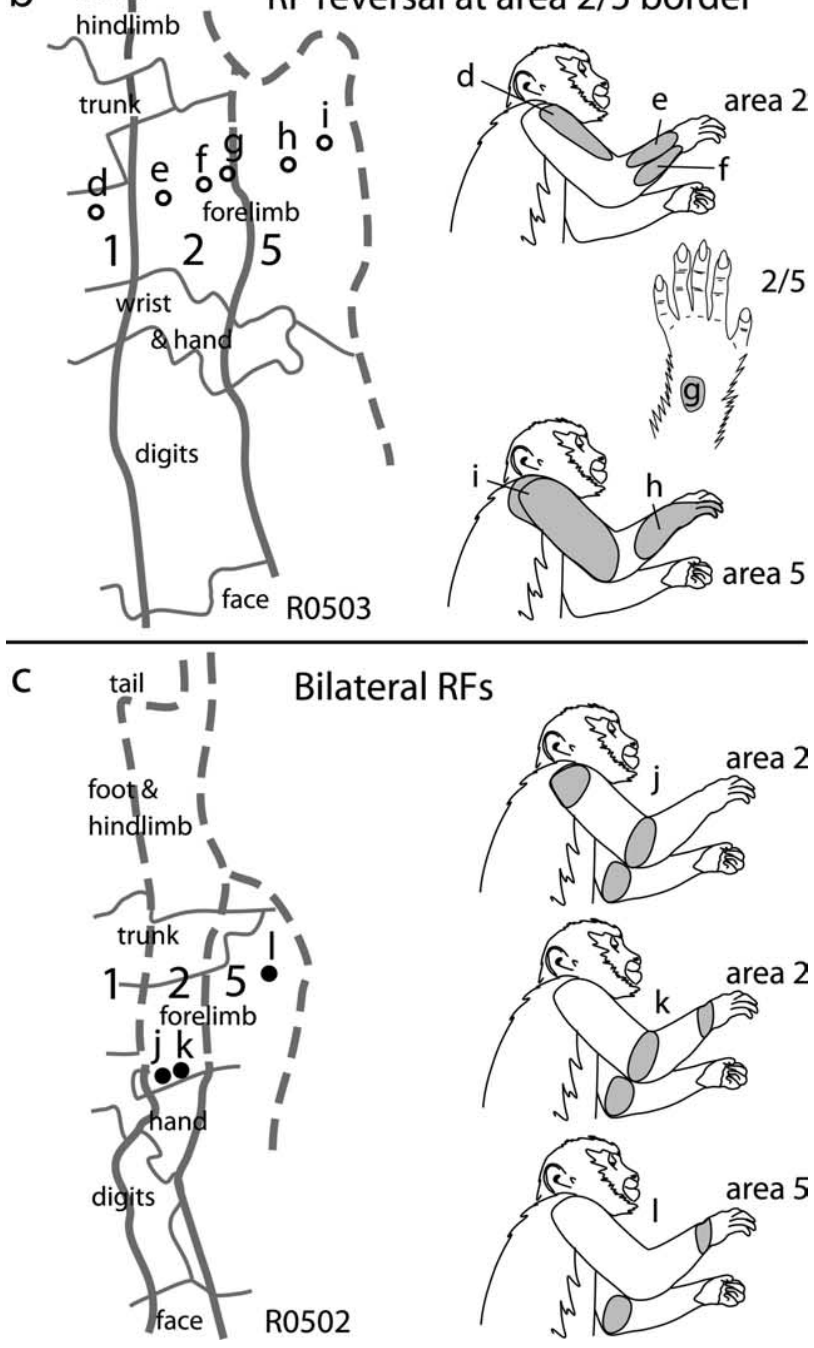

Figure 5. Rostrocaudal progressions or recording sites through areas 1, 2, and 5 demonstrating rerepresentation of body parts and reversals of receptive fields of neurons. $\boldsymbol{a}-\boldsymbol{c}$, Recording sites in areas 1, 2, and 5 and corresponding receptive fields for neurons at those sites (right) for the three monkeys used in these experiments. $\boldsymbol{a}$, Rerepresentation of body parts in areas 1, 2, and 5. Note that the receptive field size is smaller for neurons in area 1 compared with areas 2 and $5 . \boldsymbol{b}$, Progression of recording sites through the forelimb representations in areas 1,2 , and 5 , indicating a reversal in receptive field progression at the area $2 / 5$ boundary. c, Bilateral receptive fields in area 2 and ipsilateral receptive fields in area 5 in case R0502. Conventions are as in previous figures.

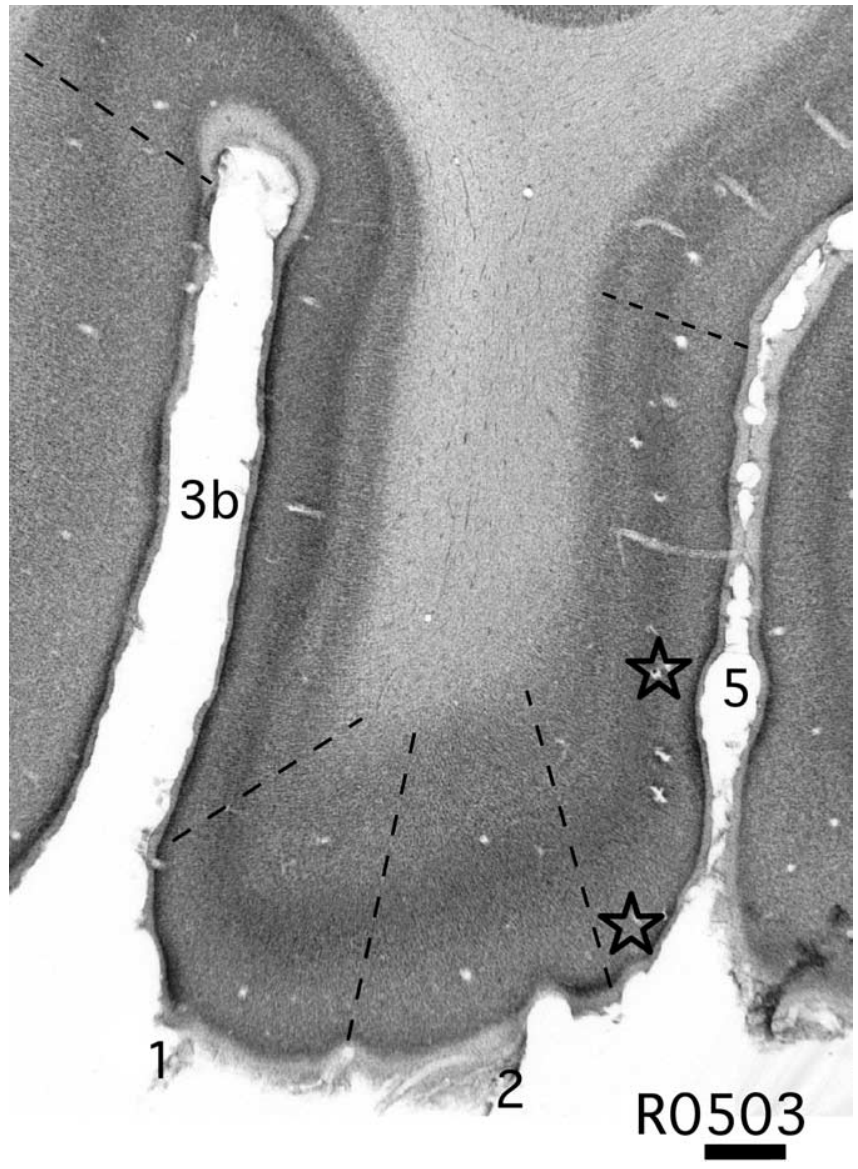

Figure 6. Lightfield digital image of a horizontally sectioned tissue that has been stained for Nissl substance in case R0503. Area $3 \mathrm{~b}$ has a densely packed, thick layer IV, whereas area 1 has a wider, less-densely packed layer IV. Area 2 appears more homogeneous than areas $3 \mathrm{~b}$ and 1 but possesses a moderately packed and wide layer IV. In area 5, layers IV and VI are more densely packed and darkly staining than those in area 2. The caudal (deep in the IPS) boundary of area 5 can be identified by a decrease in staining intensity in layer IV. Dashed lines indicate cytoarchitectonic borders. Scale bar, $1 \mathrm{~mm}$. Stars denote electrode penetrations marked with DY. Conventions are as in previous figures.

humans, regions of cortex including area 5 appear to be involved in movement planning, and these regions are active during execution and visualization of movements of the forelimb (Astafiev et al., 2003; Hanakawa et al., 2003; Diedrichsen et al., 2004). Although area 5 has been described in New World titi monkeys, it is small and poorly developed (Padberg et al., 2005).

Together, the data indicate that areas 2 and 5 are present in cebus, macaques and humans. In macaques, these areas are involved in the active discrimination of object shape and size, motor planning associated with coordinating the hands and eyes, and in generating an internal coordinate system necessary for effectively interfacing the hands with the object to be explored. Although area 2 in macaques is linked to tactile discriminations made with the hands, it is interesting that, unlike area 5 , area 2 contains a complete representation of the body. We focus on three factors that appear to contribute to the organization of area 2 (and area 5): hand morphology, use, and encephalization (see below). However, other factors, such as the need to match inputs from adjacent topographically organized fields to make context dependent comparisons (Kaas, 1997), and the need to correlate two spatial variables to specify the spatial location of a peripheral stimulus (Mountcastle, 2005b) also contribute to the organization of these fields. Thus, the organization of a cortical area is a 


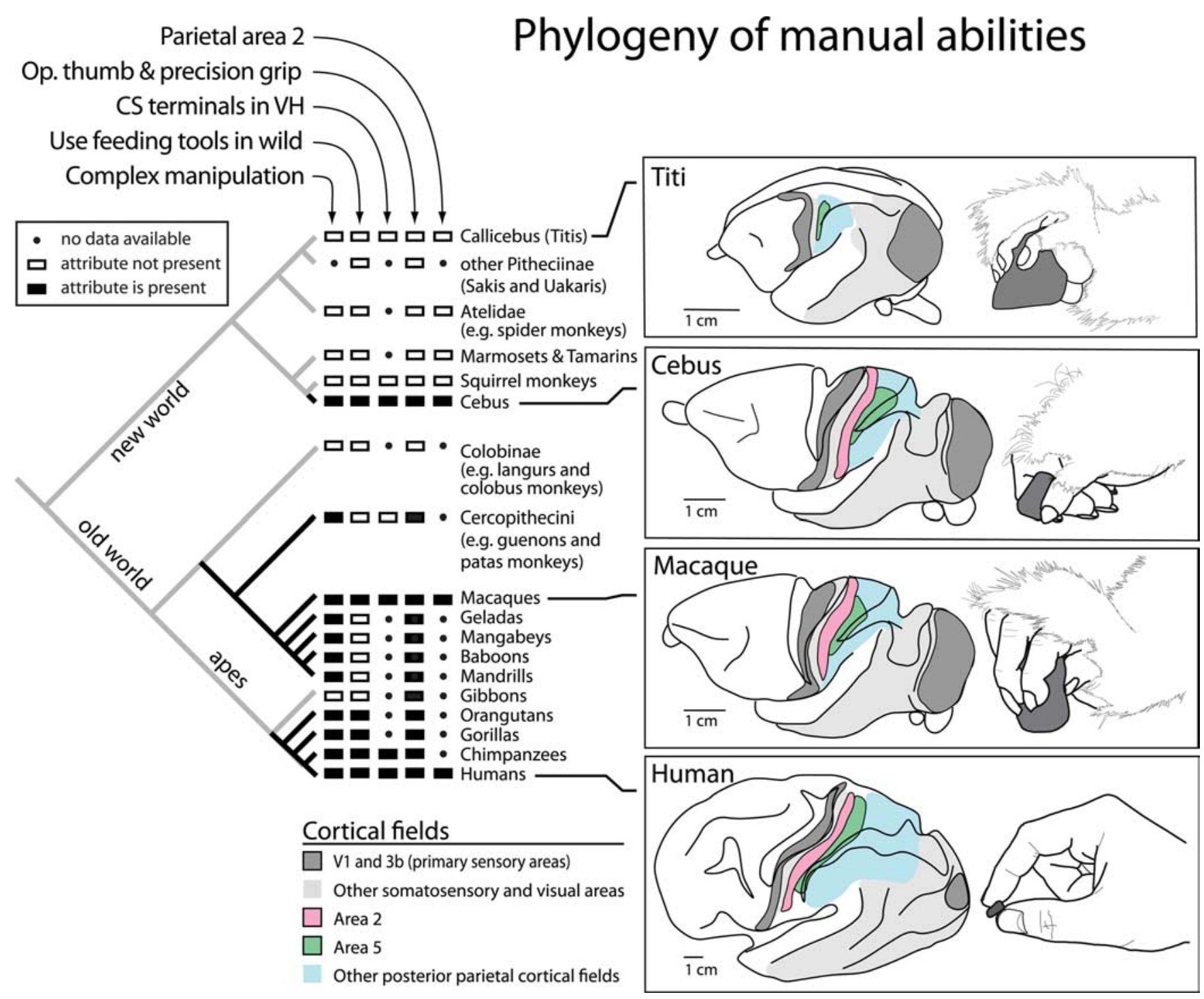

Figure 7. Left, Primate cladogram showing which primate taxa have the following characteristics related to manual control: complex manipulation (e.g., grasping food with one hand and peeling it with the other), use of feeding tools, corticospinal (CS) terminals in ventral horn (VH), opposable (or laterally opposable) thumb, and presence of parietal area 2. Filled box, Characteristic is present. Unfilled box: characteristic has been sufficiently tested and is absent. Right, Parietal areas and representative grasp postures traced from photographs in five primate species. The cladogram was adapted from van Schaik et al. (2003).

compromise between a number of competing factors that may not be individually optimized, or even intuitive, but considered together are optimal given the constraints imposed at different levels of organization from genes to molecules to brains and behaviors (Aflalo and Graziano, 2006).

What primates do with their hands and what makes this possible

In addition to the manual abilities described above, some primates combine elements in novel ways to alter the environment, and selectively use external objects that have an optimal size, shape, mass, and elasticity to serve as an extension or augmentation of the body to perform a goal directed task. Whereas this ability is highly pronounced in humans, tool use has been observed in nature in only a few nonhuman primates. For example, wild chimpanzees and orangutans select and modify thin stems to "fish" at termite mounds, or use stones to crack open nuts (Goodall, 1964; van Schaik et al., 1996, 2003; Fox et al., 1999; Boesch and Boesch-Achermann, 2000). Inter- estingly, tool use has also been observed in wild cebus monkeys (Fernandes, 1991; Fragaszy et al., 2004; Waga et al. 2006).

Such behaviors require particular bone, joint and muscle morphology that alters the mechanics of the hand, and increases the number of possible digit configurations. These behaviors also require neural control of the hand and digits. Changes in hand morphology (Napier and Napier, 1967; Rose, 1996) and corticospinal projections necessary for fine motor control of individual digits are both present in cebus monkeys (Heffner and Masterton, 1983; Bortoff and Strick, 1993; Maier et al., 1997; Lemon and Griffiths, 2005). Tool use and other sophisticated manual behaviors also involve motor planning, and seem to depend crucially on the frontal areas to which parietal cortex projects (Preuss and Goldman-Rakic, 1991). Studies of the anatomical organization of the frontal cortex indicate that cebus monkeys have well developed motor and premotor areas, much like those of macaques (Allen et al. 1978; Tian and Lynch, 1996a,b; Dum and Strick 2005; Cruz-Rizzolo et al., 2006). 
Our data indicate that some parietal areas involved in manual discrimination and motor planning associated with sophisticated hand use emerged independently in some primates. The remarkable similarity of areas 2 and 5 in two distantly related species begs the question of how this parallel organization evolved.

\section{The independent evolution of areas 2 and 5 in New and Old World monkeys}

Given that natural selection acts on individuals and their behavior, rather than on a single morphological or neural structure in isolation, it is impossible to single out an individual event that leads to the independent emergence of similar neural characteristics. Rather, evolutionary changes involving skeletal, muscular and neural features proceed in parallel (Krubitzer and Kaas, 2005) and, thus, features of the body and brain are linked (Kaas, 1997). As noted above, alterations in skeletal morphology of the hand, the frontal lobe, and corticospinal projections have occurred independently in cebus and macaque monkeys. All of these factors contribute, at least in part, to the emergence and organization of areas 2 and 5.

Another feature that is similar in cebus monkeys and macaques, and that may contribute to the parallel emergence of areas 2 and 5, is the high degree of encephalization observed in both species (Gibson, 1986; Rilling and Insel, 1999), which leads to predictable changes in the cortical phenotype. For example, with the expansion of the cortical sheet, the relative amount of cortical territory devoted to primary areas tends to decrease, and new cortical areas are added. There may be an increase in the amount of cortex devoted to morphological and behavioral specializations, such as the expansion of auditory cortex linked to echolocation in dolphins (Marino, 2006; Marino et al., 2007), the emergence of motor areas associated with the elaboration of the larynx, tongue, and lips in humans (Murphy et al., 1997; Krubitzer and Kahn, 2003), and the expansion of the parietal cortex linked to visually mediated manual behaviors in humans (Rosa and Tweedale, 2005; Krubitzer and Disbrow, 2007). Thus, the dramatic magnification of the hand representation of area 5 in cebus and macaque monkeys is not surprising given the similar organizational changes that have emerged with encephalization and morphological specialization in other mammals.

We propose that the emergence and ultimate organization of areas 2 and 5 in cebus represents the inescapable outcome of a homologous and highly constrained developmental program for the formation of cortical fields that unravels in the context of similar extrinsic events including hand morphology and use.

\section{References}

Aflalo TN, Graziano MSA (2006) Possible origins of the complex topographic organization of motor cortex: reduction of a multidimensional space onto a two-dimensional array. J Neurosci 26:6288-6297.

Ageranioti-Bélanger SA, Chapman CE (1992) Discharge properties of neurons in the hand area of primary somatosensory cortex in monkeys in relation to the performance of an active tactile discrimination task. II. Area 2 as compared to areas 3b and 1. Exp Brain Res 91:207-228.

Allen GI, Gilbert PF, Yin TC (1978) Convergence of cerebral inputs onto dentate neurons in monkey. Exp Brain Res 32:151-170.

Andersen RA, Snyder LH, Bradley DC, Xing J (1997) Multimodal representation of space in the posterior parietal cortex and its use in planning movements. Annu Rev Neurosci 20:303-330.

Astafiev SV, Shulman GL, Stanley CM, Snyder AZ, Van Essen DC, Corbetta M (2003) Functional organization of human intraparietal and frontal cortex for attending, looking, and pointing. J Neurosci 23:4689-4699.

Bernhard CG, Bohm E, Petersen I (1953) New investigations on the pyramidal system in Macaca mulatta. Experientia 9:111-112.

Boesch C, Boesch-Achermann H (2000) The chimpanzees of the Tai forest: behavioural ecology and evolution. Oxford: Oxford UP.
Bortoff GA, Strick PL (1993) Corticospinal terminations in two new-world primates: further evidence that corticoneuronal connections provide part of the neural substrate for manual dexterity. J Neurosci 13:5105-5118.

Burbaud P, Doegle C, Gross C, Bioulac B (1991) A quantitative study of neuronal discharge in areas 5,2 and 4 of the monkey during fast arm movements. J Neurophysiol 66:429-443.

Carlson M (1981) Characteristics of sensory deficits following lesions of Brodmann's areas 1 and 2 in the postcentral gyrus of Macaca mulatta. Brain Res 204:424-430.

Castiello U (2005) The neuroscience of grasping. Nat Rev Neurosci 6:726-736.

Christel MI, Fragaszy DM (2000) Manual function in Cebus apella. Digital mobility, preshaping, and endurance in repetitive grasping. Int J Primatol 21:697-719.

Coq JO, Qi H, Collins CE, Kaas JH (2004) Anatomical and functional organization of somatosensory areas of the lateral fissure of the new world titi monkey (Callicebus moloch). J Comp Neurol 476:363-387.

Cruz-Rizzolo RJ, Horta-Junior Jde A, Bittencourt JC, Ervolino E, de Oliveira JA, Casatti CA (2006) Distribution of NADPH-diaphorase-positive neurons in the prefrontal cortex of the Cebus monkey. Brain Res 1083:118-133.

Debowy DJ, Ghosh S, Ro JY, Gardner EP (2001) Comparison on neuronal firing rates in somatosensory and posterior parietal cortex during prehension. Exp Brain Res 137:269-291.

Diedrichsen J, Nambisan R, Kennerley SW, Ivry RB (2004) Independent on-line control of the two hands during bimanual reaching. Eur J Neurosci 19:1643-1652.

Dum RP, Strick PL (2005) Frontal lobe inputs to the digit representations of the motor areas on the lateral surface of the hemisphere. J Neurosci 25:1375-1386.

Felleman DJ, Nelson RJ, Sur M, Kaas JH (1983) Representations of the body surface in areas $3 \mathrm{~b}$ and 1 of postcentral parietal cortex of cebus monkeys. Brain Res 268:15-26.

Fernandes M (1991) Tool use and predation of oysters (Crassostrea rhizophorae) by the tufted capuchin, Cebus apella apella, in brackish water mangrove swamp. Primates 32:529-531.

Ferraina S, Bianchi L (1994) Posterior parietal cortex: functional properties of neurons in area 5 during an instructed-delay reaching task within different parts of space. Exp Brain Res 99:175-178.

Fleagle JG (1986) The fossil record of early catarrhine evolution. In: Major topics in primate and human evolution (Wood B, Martin L, Andrews P, eds), pp 130-149. New York: Cambridge UP.

Fleagle JG, Simons EL (1995) Limb skeleton and locomotor adaptations of Apidium phiomense, an Oligocene anthropoid from Egypt. Am J Phys Anthropol 97:235-289.

Fox EA, Sitompul AF, van Schaik CP (1999) Intelligent tool use in wild Sumatran orangutans. In: The mentalities of gorillas and orangutans: comparative perspectives (Parker ST, Mitchell GW, Miles HL, eds), pp 99-116. West Nyack, NY: Cambridge UP.

Fragaszy D, Izar P, Visalberghi E, Ottoni EB, de Oliveira MG (2004) Wild capuchin monkeys (Cebus libidinosus) use anvils and stone pounding tools. Am J Primatol 64:359-366.

Fragaszy DM (1983) Preliminary quantitative studies of prehension in squirrel monkeys (Saimiri sciureus). Brain Behav Evol 23:81-92.

Gallyas F (1979) Silver staining of myelin by means of physical development. Neurology 1:203-209.

Gardner E (1988) Somatosensory cortical mechanisms of feature detection in tactile and kinesthetic discrimination. Can J Physiol Pharmacol 66:439-454.

Gibson KR (1986) Cognition, brain size, and the extraction of embedded food resources. In: Primate ontogeny, cognition, and social behavior (Else JG, Lee PC, eds), pp 93-105. Cambridge, UK: Cambridge UP.

Goodall J (1964) Tool-using and aimed throwing in a community of freeliving chimpanzees. Nature 201:1264-1266.

Graziano MS, Cooke DF, Taylor CS (2000) Coding the location of the arm by sight. Science 290:1782-1786.

Hall BK (2003) Descent with modification: the unity underlying homology and homoplasy as seen through an analysis of development and evolution. Biol Rev 78:409-433.

Hanakawa T, Immisch I, Toma K, Dimyan MA, Van Gelderen P, Hallett M (2003) Functional properties of brain areas associated with motor execution and imagery. J Neurophysiol 89:989-1002. 
Heffner R, Masterton RB (1983) The role of the corticospinal tract in the evolution of human digital dexterity. Brain Behav Evol 23:165-183.

Hyvärinen J, Poranen A (1978) Receptive field integration and submodality convergence in the hand area of the post-central gyrus of the alert monkey. J Neurophysiol 283:539-556.

Iriki A, Tanaka M, Iwamura Y (1996) Coding of modified body schema during tool use by macaque postcentral neurons. NeuroReport 7:2325-2330.

Iwamura Y (2000) Bilateral receptive field neurons and callosal connections in the somatosensory cortex. Philos Trans R Soc Lond B Biol Sci 355:267-273.

Iwamura Y, Tanaka M, Iriki A, Taoka M, Toda T (2002) Processing of tactile and kinesthetic signals from bilateral sides of the body in the postcentral gyrus of awake monkeys. Behav Brain Res 135:185-190.

Kaas JH (1997) Topographic maps are fundamental to sensory processing. Brain Res Bull 44:107-112.

Kalaska JF (1996) Parietal cortex area 5 and visuomotor behavior. Can J Physiol Pharmacol 74:483-498.

Krubitzer L, Disbrow E (2007) The evolution of parietal areas involved in hand use in primates. In: The senses: a comprehensive reference, Vol V, Somatosensation (Kaas JH, Gardner EP, eds). Oxford: Elsevier.

Krubitzer L, Kaas JH (2005) The evolution of the neocortex in mammals: how is phenotypic diversity generated? Curr Opin Neurobiol 15:444-453.

Krubitzer L, Kahn DM (2003) Nature versus nurture revisited: an old idea with a new twist. Prog Neurobiol 70:33-52.

Krubitzer L, Clarey J, Tweedale R, Elston G, Calford M (1995) A redefinition of somatosensory areas in the lateral sulcus of macaque monkeys. J Neurosci 15:3821-3839.

Kuypers HG (1981) Anatomy of the descending pathways. In: Handbook of neurophysiology - the nervous system II (Brookhart JM, Mountcastle VB, eds), pp 597-666. Bethesda, MD: Am Physiol Soc.

Lacquaniti F, Guigon E, Bianchi L, Ferraina S, Caminiti R (1995) Representing spatial information for limb movement: the role of area 5 in monkey. Cereb Cortex 5:391-409.

Lemon RN, Griffiths J (2005) Comparing the function of the corticospinal system in different species: organizational differences for motor specialization? Muscle Nerve 32:261-279.

Maier MA, Olivier E, Baker SN, Kirkwood PA, Morris T, Lemon RN (1997) Direct and indirect corticospinal control of arm and hand motorneurons in the squirrel monkey (Saimiri sciuresis). J Neurophysiol 78:721-733.

Marino L (2006) Cetacean brain evolution. In: Evolution of nervous systems, a comprehensive reference, Vol III (Kaas JH, Krubitzer LA, eds), pp 261-266. Oxford: Elsevier.

Marino L, Connor RC, Fordyce RE, Herman LM, Hof PR, Lefebvre L, Lusseau D, McCowan B, Nimchinsky EA, Pack AA, Rendell L, Reidenberg JS, Reiss D, Uhen MD, Van der Gucht E, Whitehead H (2007) Cetaceans have complex brains for complex cognition. PLoS Biol 5:e139.

Merzenich MM, Kaas JH, Sur M, Lin CS (1978) Double representation of the body surface within cytoarchitectonic areas $3 \mathrm{~b}$ and 1 in "SI" in the owl monkey (Aotus trivirgatus). J Comp Neurol 181:41-74.

Moore C, Stern C, Corkin S, Fischl B, Gray A, Rosen B, Dale A (2000) Segregation of somatosensory activation in the human rolandic cortex using fMRI. J Neurophysiol 84:558-569.

Mountcastle VB (2005a) The evolution and structure of the hand, Chapter 2. In: The sensory hand, pp 27-50. Cambridge, MA: Harvard UP.

Mountcastle VB (2005b) Postcentral somatic sensory cortical areas in primates, Chapter 10. In: The sensory hand, pp 260-300. Cambridge, MA: Harvard UP.

Mountcastle VB (2005c) The sensory hand. Cambridge, MA: Harvard UP.

Mountcastle VB, Lynch JC, Georgopoulos A, Sakata H, Acuña C (1975) Posterior parietal association cortex of the monkey: command functions for operations within extrapersonal space. J Neurophysiol 38:871-908.

Murphy K, Corfield DR, Guz A, Fink GR, Wise RJ, Harrison J, Adams L (1997) Cerebral areas associated with motor control of speech in humans. J Appl Physiol 83:1438-1447.

Murray EA, Mishkin M (1984) Relative contributions of SII and area 5 to tactile discrimination in monkeys. Behav Brain Res 11:67-83.

Nakajima K, Maier MA, Kirkwood PA, Lemon RN (2000) Striking differences in transmission of corticospinal excitation to upper limb motoneurons in two primate species. J Neurophysiol 84:698-709.
Napier JR, Napier PH (1967) A handbook of living primates. Morphology, ecology and behaviour of nonhuman primates. London: Academic.

Padberg J, Disbrow E, Krubitzer L (2005) The organization and connections of anterior and posterior parietal cortex in titi monkeys: do New World monkeys have an area 2? Cereb Cortex 15:1938-1963.

Patel NH (2003) The ancestry of segmentation. Dev Cell 5:2-4.

Pons TP, Garraghty PE, Cusick CG, Kaas JH (1985) The somatotopic organization of area 2 in macaque monkeys. J Comp Neurol 241:445-466.

Preuss TM, Goldman-Rakic PS (1991) Ipsilateral cortical connections of granular frontal cortex in the strepsirhine primate Galago, with comparative comments on anthropoid primates. J Comp Neurol 310:507-549.

Randolph M, Semmes J (1974) Behavioral consequences of selective subtotal ablations in the postcentral gyrus of Macaca mulatta. Brain Res 70:55-70.

Rilling JK, Insel TR (1999) The primate neocortex in comparative perspective using magnetic resonance imaging. J Hum Evol 37:191-223.

Rosa MG, Tweedale R (2005) Brain maps, great and small: lessons from comparative studies of primate visual cortical organization. Philos Trans R Soc Lond B Biol Sci 360:665-691.

Rosa MG, Soares JG, Fiorani Jr M, Gattass R (1993) Cortical afferents of visual area MT in the Cebus monkey: possible homologies between New and Old World monkeys. Vis Neurosci 10:827-855.

Rose MD (1996) Functional morphological similarities in the locomotor skeleton of miocene catarrhines and platyrrhine monkeys. Folia Primatol 66:7-14.

Rushworth MF, Nixon PD, Passingham RE (1997) Parietal cortex and movement. Exp Brain Res 117:311-323.

Rutishauser R, Moline P (2005) Evo-devo and the search for homology ("sameness") in biological systems. Theory Biosci 124:213-241.

Showell C, Binder O, Conlon FL (2004) T-box genes in early embryogenesis. Dev Dyn 229:201-218.

Snyder LH, Batista AP, Andersen RA (1997) Coding of intention in the posterior parietal cortex. Nature 386:167-170.

Spinozzi G, Truppa V, Lagana T (2004) Grasping behavior in tufted capuchin monkeys (Cebus apella): grip types and manual laterality for picking up a small food item. Am J Phys Anthropol 125:30-41.

Stepniewska I, Fang PC, Kaas JH (2005) Microstimulation reveals specialized subregions for different complex movements in posterior parietal cortex of prosimian galagos. Proc Natl Acad Sci USA 102:4878-4883.

Sur M, Nelson RJ, Kaas JH (1982) Representations of the body surface in cortical areas $3 \mathrm{~b}$ and 1 of squirrel monkeys: comparisons with other primates. J Comp Neurol 211:177-192.

Taoka M, Toda T, Iwamura Y (1998) Representation of the midline trunk, bilateral arms, and shoulders in the monkey postcentral somatosensory cortex. Exp Brain Res 123:315-322.

Taoka M, Toda T, Iriki A, Tanaka M, Iwamura Y (2000) Bilateral receptive field neurons in the hindlimb region of the postcentral somatosensory cortex in awake macaque monkeys. Exp Brain Res 134:139-146.

Tian JR, Lynch JC (1996a) Functionally defined smooth and saccadic eye movement subregions in the frontal eye field of Cebus monkeys. J Neurophysiol 76:2740-2753.

Tian JR, Lynch JC (1996b) Corticocortical input to the smooth and saccadic eye movement subregions of the frontal eye field in Cebus monkeys. J Neurophysiol 76:2754-2771.

Tigges J, Nakagawa S, Tigges M (1979) Efferents of area 4 in a South American monkey (Saimiri). I. Terminations in the spinal cord. Brain Res 171:1-10.

Van Essen DC, Maunsell JH (1980) Two-dimensional maps of the cerebral cortex. J Comp Neurol 191:255-281.

van Schaik CP, Fox EA, Sitompul AF (1996) Manufacture and use of tools in wild Sumatran orangutans. Naturwissenschaften 83:186-188.

van Schaik CP, Deaner RO, Merrill MY (2003) The conditions for tool use in primates: implications for the evolution of material culture. J Hum Evol 36:719-741.

Waga IC, Dacier AK, Pinha PS, Tavares MC (2006) Spontaneous tool use by wild capuchin monkeys (Cebus libidinosus) in the Cerrado. Folia Primatol (Basel) 77:337-344.

Wise SP, Boussaoud D, Johnson PB, Caminiti R (1997) Premotor and parietal cortex: corticocortical connectivity and combinatorial computations. Annu Rev Neurosci 20:25-42.

Wolpaw JR (1980) Correlations between task-related activity and responses to perturbation in primate sensorimotor cortex. J Neurophysiol 44:11221138 . 